\title{
LONG-EARED OWL NESTING PHENOLOGY AND HABITAT IN CENTRAL ALBERTA
}

LISA TAKATS PRIESTLEY ${ }^{1}$, CHUCK PRIESTLEY²

${ }^{1}$ Beaverhill Bird Observatory

2 STRIX Ecological Consulting

The Long-eared Owl (Asio otus) is a secretive nocturnal owl found in open and sparsely forested habitats across North America and Eurasia between $30^{\circ}$ and $65^{\circ} \mathrm{N}$ latitude. ${ }^{12}$ In Alberta, it is found in the Boreal Forest, Foothills, Grassland, Parkland, and Rocky Mountain Natural Regions, where they prefer fragmented habitats containing dense woodlands or shelterbelts for nesting and roosting and open areas for hunting. ${ }^{7}$ It is a year round-resident, but it's overwintering ecology is relatively unknown. ${ }^{2,7}$ The Long-eared Owl is considered 'Secure' in Alberta, ${ }^{1}$ although information on populations, trends, specific habitat use and even distribution are poorly understood. ${ }^{9,12}$ Banding data from Saskatchewan suggest there is inconclusive evidence for population declines, and that populations are cyclical. ${ }^{10}$

The first step in managing wildlife populations is having knowledge of distribution and abundance. ${ }^{14}$ Owls are elusive, which makes them difficult to study and monitor. ${ }^{8}$ In 1988, a volunteer raptor nest card program was

initiated by Alberta Environment and Sustainable Resource Development (Alberta ESRD) to encourage raptor banders and researchers to collect additional information on nest locations and breeding habitat use of birds of prey. This program developed into the Prairie Nest Record Scheme and Alberta Raptor Nest Card Programs. The Alberta Raptor Nest Card data are stored with Beaverhill Bird Observatory and data are submitted to Alberta ESRD and the national NestWatch Program run by Bird Studies

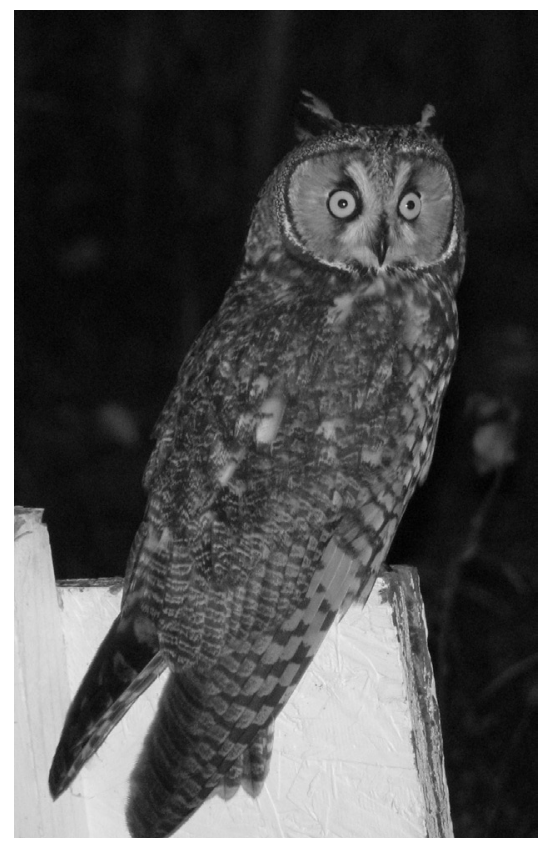


Canada. The Beaverhill Bird Observatory has been analyzing the phenology of a variety of raptor species from data collected in the nest card program. ${ }^{16,17,18,19}$ This paper addresses the timing of nesting and breeding habitat of Long-eared Owls nesting in central Alberta, based on nest banding data collected between 1987 and 2011.

\section{Methods}

The study area was located in central Alberta (latitudes $52.5^{\circ}$ to $54.6^{\circ}$, longitudes $110.5^{\circ}$ to $114.2^{\circ}$ ), surrounding the city of Edmonton. Nests were located in the Aspen Parkland and Boreal Natural Regions. Nests were found by one or more of: 1) visiting known nesting sites of other species that build the stick nests; 2) looking for birds on territory in the spring; or 3) through contact with landowners who found pairs or nests on their land. For each nest, banders collected information on nest type (natural or manmade), nest height, tree height, nest habitat, surrounding land use, and banding data including an estimate of the age (in days) of the young at the banding time..$^{3,20}$ The age at banding was determined by experienced banders using descriptions of growth and development. ${ }^{20,23}$ Developmental changes include, eyes open at five days, second natal down at two weeks, and flight feathers developing into their second week with vanes erupting as they are ready to leave the nest in the third week. All data was entered into Microsoft Excel for analysis.

The estimated date of Longeared Owl hatching was calculated by subtracting the age (in days) of the oldest-aged young from the date of banding. Laying date was estimated by subtracting the number of days required for incubation from the estimated hatch date. Fledging date was estimated by adding the number of days required for fledging to the estimated hatch date. The time required for incubation and fledging was determined as the largest number of days reported in published literature. The estimated number of days needed for incubation and fledging used for this paper were 28 and 21 days respectively. ${ }^{6,12,23}$

\section{Results and Discussion}

There were 59 nest records submitted for Long-eared Owls. The average laying date was May 7 (range Apr. 11 to June 11) (Figure 1), the average hatching date was June 4 (range May 9 to July 9), and the average fledging date was June 25 (range May 30 to July 30) (Figure 2). In Idaho, first clutches were usually laid between mid-March and midMay. ${ }^{11}$ 


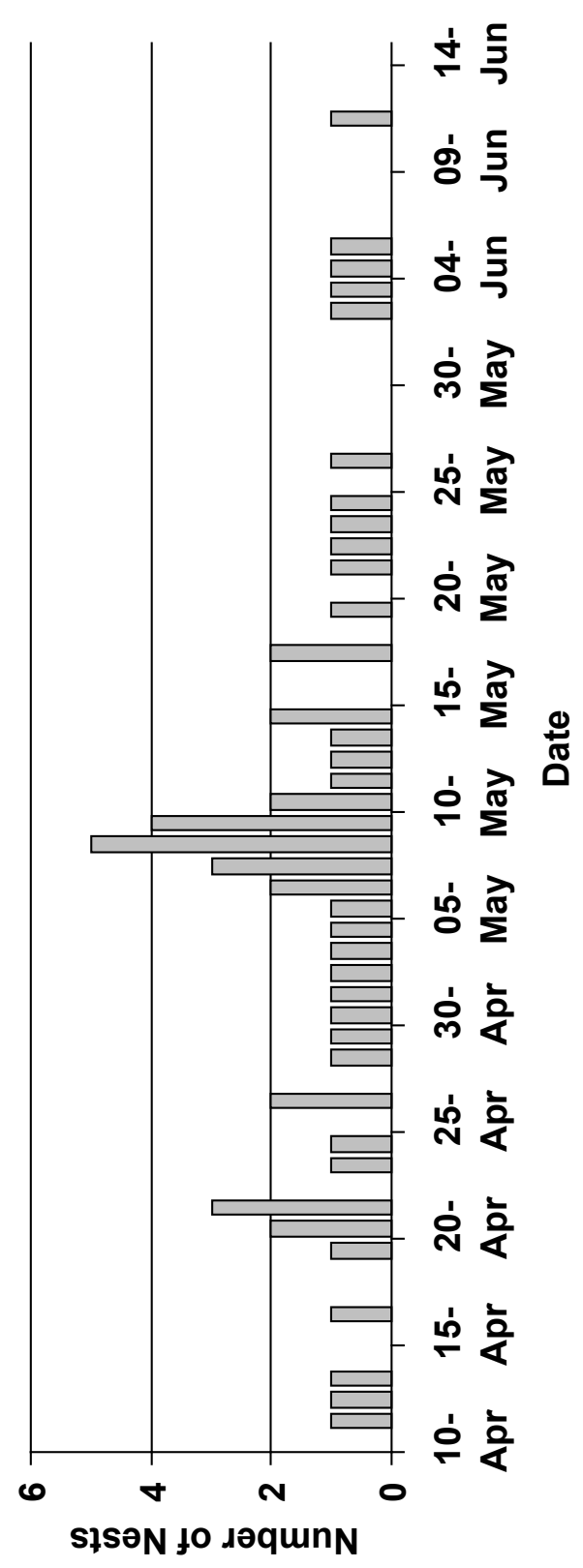

Figure 1. Estimated egg laying dates of the Long-eared Owl in central Alberta 1987 to 2010. 
Of the 59 nests, 6 failed (no young fledged) and 53 were considered successful (one or more young were ready to fledge at banding time). Egg counts were present for 25 nests, and averaged 4.9 eggs per nest (range 3 to $7, S D=0.93$ ). Murray (1976) found the average clutch size for Long-eared Owls in North America was 4.5 eggs per nest (range 2-10), and number increased as you went north and west. Of the successful nests $(n=52)$ the average brood size was 3.7 young per nest (range 1-6). Average number of young fledged per successful nest reported ranged from 3 to 4.5 in the United States. ${ }^{5,12}$
There were habitat data available for 57 Long-eared Owl nests. Fifty-four nests were stick nests and three were manmade platforms. Twenty-six stick nests were described in further detail as being originally built by American Crow (Corvus brachyrhynchos) (6), Black-billed Magpie (Pica pica) (16), Cooper's Hawk (Accipiter cooperii) (2), Sharp-shinned Hawk (Accipiter striatus) (1), and squirrel (1). Most (44\%) nests were found in willow, and the average height of nests was 14.8 feet (range 7 to 36 feet, SD=7.04). Nests were found most often in Grassland/ Shrubland (Table 2), and were usually in isolated groups of trees or shrubs surrounded by

Table 1. Long-eared Owl nest-tree types in central Alberta.

\begin{tabular}{lc}
\hline Nest Tree -type & Number of Nests (\%) \\
\hline Black Spruce (Live) & $11(19)$ \\
Maple (Live) & $1(2)$ \\
Trembling Aspen (Live) & $6(11)$ \\
White Spruce (Live) & $14(25)$ \\
willow (Dead) & $2(4)$ \\
willow (Live) & $23(40)$ \\
\hline
\end{tabular}

Table 2. Habitat-types surrounding Long-eared Owl nests in central Alberta.

Habitat-type

Coniferous Forest

Forest (type not specified)

Grassland/Shrubland

Mixedwood Forest

Parkland

Urban Treed/Shrub
Number of Nests (\%)

$6(11)$

2 (4)

28 (49)

$14(25)$

$5(9)$

$2(4)$ 
crops. Other habitats described nearby included horse pasture, overgrown fields, unoccupied and occupied farmsteads. Many nests were found in the same woodlots for multiple years, and on the rare occasion the same nest was used in multiple years.

Throughout their North American breeding range, Long-eared Owls have been found nesting in dense or brushy vegetation amidst open habitats. ${ }^{12}$ They used hedgerows along farm fields in Montana (D. Holt pers. comm. 2010). Typically stick nests were used and of 130 nests found in southwestern Idaho, 91 were built by Black-billed Magpie, 38 by American Crow, and one in a cliff cavity. ${ }^{13}$ Longeared Owls also commonly use nests built by Common Ravens (Corvus corax), Cooper's Hawks, and various Buteo spp. 3,4,21

Population declines of Long-eared Owls have been caused by habitat alteration, forest succession, urbanization, competition with Great Horned Owls (Bubo virginianus), loss of habitat for prey species, rodenticides, shooting, and habitat loss..$^{9,12}$ If habitat alteration is to occur, occupied nest sites need to be protected. Although young Long-eared Owls leave the nest at about 21 days, they are still flightless (branching stage), and reside in surrounding vegetation. ${ }^{11,23}$ They are capable of short flights at 35 days and are fed by parents for up to 11 weeks. ${ }^{22}$ Therefore, occupied Long-eared Owl nests and the adjacent habitat should not be cleared from mid-April through mid-August in central Alberta.

\section{Acknowledgements}

Funding from Alberta Ecotrust, Alberta Conservation Association, Alberta Sustainable Resource Development, Alberta Sport, Recreation, Parks and Wildlife Foundation, Community Spirit Program, AGLC, Nature Canada Charles Labatiuk Fund and Beaverhill Bird Observatory is greatly appreciated. The new raptor nest card template was produced in cooperation with Alberta Sustainable Resource Development, Canadian Wildlife Service, Federation of Alberta Naturalists, and Bird Studies Canada and is available on Beaverhill Bird Observatory's website at http:// www.beaverhillbirds.com/ bboraptorsnests.htm. We thank Ray Cromie, Al DeGroot, Hardy Pletz, Violet Pletz, and Beaverhill Bird Observatory for their data contributions. The continuing cooperation of landowners is of great value to this program. We thank the editors and an anonymous reviewer for their comments on an earlier draft of this paper. 


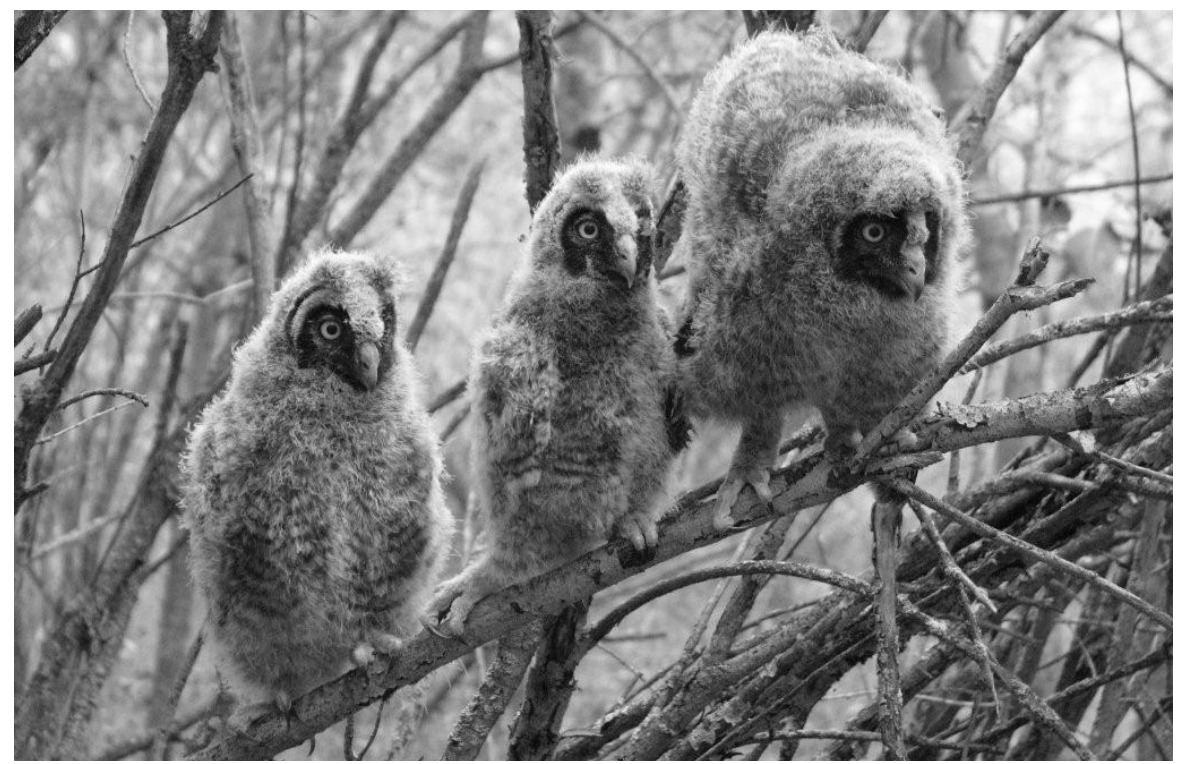

\section{References}

1. ALBERTA SUSTAINABLE RESOURCE DEVELOPMENT (2010) The general status of Alberta wild species 2010. Alberta Sustainable Resource Development, Edmonton, AB. On-line at: http://www.srd.alberta. ca/FishWildlife/SpeciesAtRisk/ eralStatusOfAlbertaWildSpecies/ tatusOfAlbertaWildSpecies2010/ SearchForWildSpeciesStatus. aspx

2. Beck BH, Beck JA Jr (1997) Winter owl surveying in central Alberta. Page 518 in J. R. Duncan, D. H. Johnson, and T. H. Nicholls (eds.) , Biology and conservation of owls of the Northern Hemisphere: 2nd International Symposium, February 5-9 1997, Winnipeg, Manitoba. U.S.Department of Agriculture, Forest Service,
General Technical Report NC190, St. Paul, MN.

3. Bent AC (1938) Life histories of North American birds of prey, pt. 2. U.S. Natl. Mus. Bull. No. 170.

4. Bloom PH (1994) The biology and current status of the Longeared Owl in coastal southern California. Bull. S. Ca. Acad. Sci. 93:1-12.

5. Bull EL, Wright AL, Henjum MG (1989) Nesting and diet of Longeared Owls in conifer forests, Oregon. Condor 91:908-912.

6. Cramp S (1985) The birds of the western Palearctic. Vol. 4. Oxford Univ. Press, Oxford. 
7. Federation of Alberta Naturalists (2007) The atlas of breeding birds of Alberta, a second look. Federation of Alberta Naturalists, Edmonton, AB. Pp. 278-279.

8. Fisher JT, Takats PriestlyL, Muhly T, Huggard D, Bayne E, Nielsen $S$ (2011) Recommendations for an owl monitoring pilot study in northeast Alberta. Rare Animals Monitoring Team, Ecological Monitoring Committee for the Lower Athabasca, Alberta. Online: http://emcla.ca/wp-content/ uploads/2012/05/EMCLA-OwlReport-2011_FINAL.pdf

9. Holt DW (1997) The longeared owl (Asio otus) and forest management: a review of the literature. Journal of Raptor Research 31(2): 175-186.

10. Houston CS (2005) Longeared owls, Asio otus: a review of North American banding. Canadian Field Naturalist 119(3): 395-402.

11. Marks JS (1986) Nest-site characteristics and reproductive success of Long-eared Owls in southwestern Idaho. Wilson Bulletin 98:547-560.

12. Marks JS, Evans DL, Holt DW (1994) Long-eared Owl (Asio otus), The Birds of North America Online (A. Poole, Ed.). Ithaca: Cornell
Lab of Ornithology; Retrieved from the Birds of North America Online: http://bna.birds.cornell. edu/bna/species/133doi:10.2173/ bna.133

13. Marks JS, Yensen E (1980) Nest sites and food habits of Long-eared Owls in southwestern Idaho. Murrelet 61:86-91.

14. Mosher JA, Fuller MR (1996) Surveying woodland hawks with broadcasts of Great Horned Owl vocalizations. Wildlife Society Bulletin 24: 531-536.

15. Murray GA (1976) Geographic variation in the clutch sizes of seven owl species. Auk 93:602613.

16. Priestly L (2005a) Phenology of three raptor species in central Alberta based on nest banding records. Blue Jay 63(1): 26-30.

17. Priestly L (2005b) Northern goshawk and barred owl phenology in Alberta. Nature Alberta 35(2): 10-12.

18. Priestly $L$ (2008) The nesting phenology of Northern Saw-whet Owl and Boreal Owl in central Alberta. Nature Alberta 38(3): 20-25.

19. Priestly L, Degroot E (2010). Nesting phenology and fledging success in central Alberta. Nature Alberta 39(3): 35-38. 
20. Pyle P (1997) The identification guide to North American birds: part 1. Slate Creek Press, Bolinas, CA. $732 \mathrm{pp}$.

21. Stophlet JJ (1959) Nesting concentration of Long-eared Owls in Cochise County, Arizona. Wilson Bulletin 71: 97-99.
22. Ulmschneider H (1990) Postnesting ecology of the Long-eared Owl (Asio otus) in southwestern Idaho. Master's Thesis. Boise State University, Boise, ID.

23. Wijnandts $H$ (1984) Ecological energetics of the Long-eared Owl (Asio otus). Ardea 72:1-92.
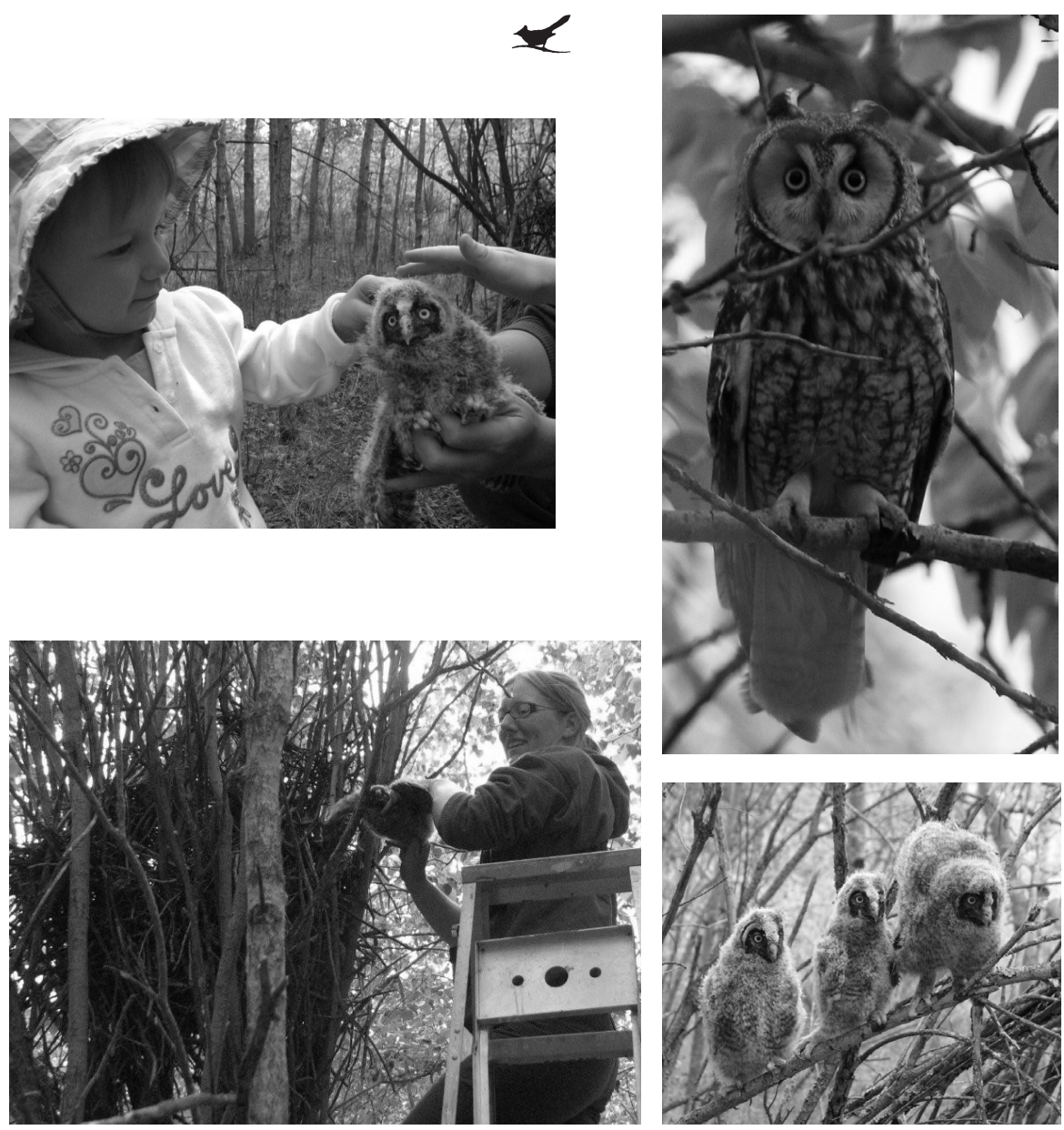